\title{
Effects of Soap Fiber Structure on Boundary Lubrication of Lithium Soap Greases
}

\author{
Atsushi Yokouchi ${ }^{1)^{*}}$, Michita Hokao ${ }^{1)}$ and Joichi Sugimura ${ }^{2)}$ \\ ${ }^{1)}$ Research and Development Center, NSK Corporation \\ 1-5-50 Kugenumashinmei, Fujisawa-shi, Kanagawa 251-8501, Japan \\ ${ }^{2)}$ Department of Mechanical Engineering, Kyushu University \\ 744 Motooka, Nishi-ku, Fukuoka 819-0395, Japan \\ *Corresponding author: yokouchi@nsk.com
}

( Manuscript received 30 July 2010; accepted 28 February 2011; published 31 March 2011 )

\begin{abstract}
This paper describes the influence of fiber length of lithium-soap thickener of greases on friction under boundary lubrication conditions. Ball-on-disk sliding tests were conducted with lithium soap greases with polyol ester as the base oil. The tests revealed that the greases had a lower friction coefficient than that for the base oil. The grease with a long soap fiber structure had a lower friction coefficient than that for the grease with a short soap fiber structure. The tests with only soap fibers showed that the soap fibers had better lubricity than the base oil under the boundary conditions tested, but there was little difference in the lubricity of the longer fibers and the shorter fibers. The partial coat tests revealed that the grease with longer soap fibers was easily entrained into the contact. It was concluded that this entrainment capability of the grease led to favorable lubrication to maintain low friction coefficient.
\end{abstract}

Keywords: grease, thickener, fiber, friction, boundary lubrication

\section{Overview}

Grease is widely used in rolling-contact bearings, and is the principal component which directly influences the lubrication performance. Grease lubrication depends on grease components including base oils, their viscosity, thickeners and their concentration, which are chosen to meet lubricating performances required $^{1-4)}$.

Structure of thickeners is one of the most important factors that affect physical properties and resulting frictional behaviors of greases. Greases with the same composition provide different friction coefficients when they have different thickener structures. Kita and Yamamoto ${ }^{5,6)}$ reported that the soap fiber structures of lithium soap greases with mineral oil were affected by the heating-cooling conditions in their manufacturing process, and that the structure affected the properties of the greases.

They also studied boundary lubrication of greases with different soap fiber structures. They found that the strength of the soap fiber structure against shear force dominated the boundary friction properties of the greases. Grease with longer and thicker fibrous soap formed a harder three-dimensional network structure.
As their soap fiber structure was not easily broken down under shear, they worked as a protective film on the sliding surfaces to provide low friction coefficient ${ }^{7}$.

Kimura et al. $^{8)}$ found that, in their studies with polyol ester-based lithium-soap greases, the retention time near the melting temperature during the grease manufacturing process and the addition of crystal-growth promoting agents affected the fiber shape, and in turn affected grease properties. Grease with long fiber soap showed a small worked penetration value after the cooling process. However, they did not study the dependence of the friction and wear properties on the soap fiber structure.

Observation of grease lubricating films with optical interferometry has gained our knowledge about their behaviors. Cann studied the influence of grease structures of various types of mineral-oil based greases on the formation of point contact EHL films under fully-flooded to starved conditions ${ }^{9)}$. She confirmed that, under starved conditions at higher speeds, a solid layer of degraded thickener particles was formed at the center of the contact zone, and hydrodynamic film formation was localized at the side of the contact zone, where the base oil was replenished from the bulk grease at the sides of the rolling track. Cann and Lubrecht summarized the grease lubrication mechanisms under 
fully-flooded to starved conditions, with a strong emphasis on replenishment of the oil film ${ }^{10)}$.

In the further studies by Cann's group, they focused on rheology and shear stability of greases ${ }^{11)}$. They reported that, based on the measurement of rheological properties with a cone-on-plate rotational viscometer, grease with higher yield stress, i.e. more resistant to shear, has lower capability to release oil and hence lower replenishing capability. Progressively worked, degraded greases exhibited better oil release and thus had increased the replenishing capability. Hurley and Cann confirmed this shear degradation under rolling contact with infrared spectroscopy ${ }^{12)}$. Observation of grease thickeners were also made by Eriksson et al., who used a high speed video camera to find that grease thickener fibers were stretched both before entering the contact and during their passage across the contact ${ }^{13)}$.

From the measurement of friction coefficient, Hurley and Cann found that greases exhibited lower friction at low speeds than that of the base oils, and they ascribed the low friction to physical deposition of thickener-rich grease boundary layer ${ }^{14)}$. More recently, Cann confirmed this in rolling sliding tests for different grease thickener types and infrared reflection analysis, and emphasized the role of the thickeners in practice in rolling element bearings ${ }^{15)}$. With all these works, however, the details of the effect of thickener structures on boundary lubrication have not yet been made clear.

In this study, ball-on-disk tests were conducted in order to explore the influence of soap fiber length of grease thickener on friction and wear properties in boundary lubrication. The sliding tests were made at low sliding speed without additional supply of grease during the tests, and with the normal load being increased stepwise. The effects of soap fiber length are discussed by focusing on the boundary lubrication of the soap fibers and the capability of grease to be entrained into the contact.

\section{Experimental}

\subsection{Test greases}

Two types of greases with different soap fiber lengths were used. One is with short fibers E03S, and the other is with longer fibers E03L. They both are composed of lithium 12-hydroxystearate thickener and an ester base oil E03, and do not contain additives. Table 1 lists their properties and Fig. 1 shows the images of the soap fibers.

The shape of soap fibers of E03S was uniform and the typical fiber length was $0.4 \mu \mathrm{m}$. E03L was featured by long fibers with typical fiber length of $10 \mu \mathrm{m}$, however E03L also contained short fibers. The shape of long fibers in E03L seemed to be thick and twisted little compared to general long soap fibers ${ }^{6,8)}$. The penetration of E03L with long soap fibers was larger than that of E03S with short fibers. This result did not conform to the report of general long fibers ${ }^{8)}$, however the report of
Table 1 Properties of greases

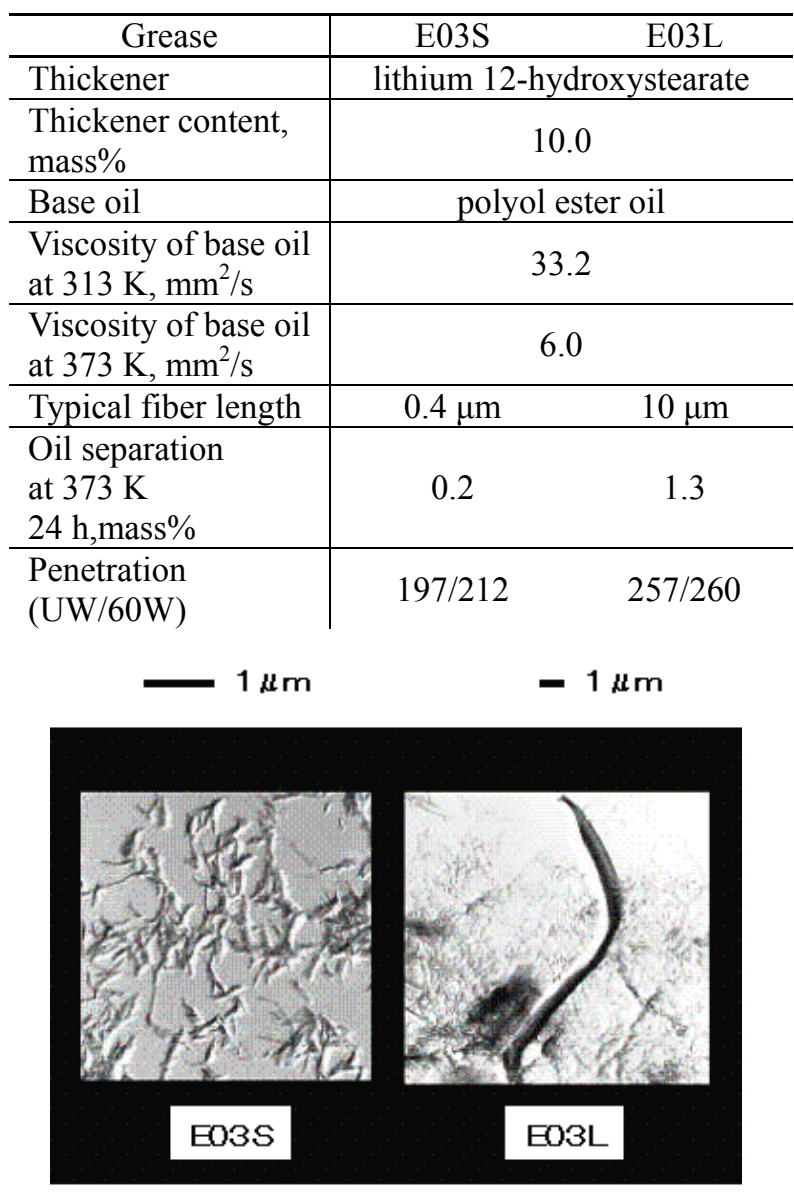

Fig. 1 Soap fibers of the greases

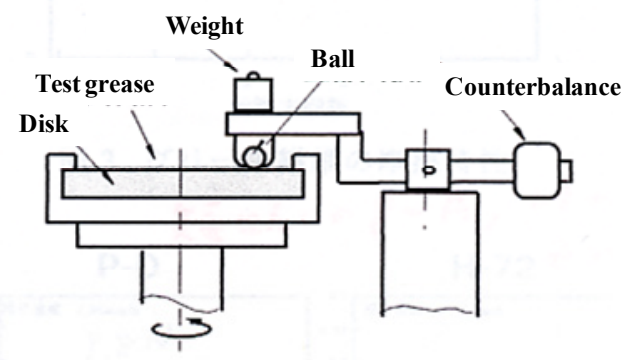

Fig. 2 Ball-on-disk test rig

Kita and Yamamoto showed little relationship between soap length and penetration ${ }^{6}$.

\subsection{Test rig and test conditions}

The ball-on-disk test rig used in this study is shown in Fig. 2. A ball of $6.5 \mathrm{~mm}$ diameter was used as the stationary upper test piece, while a disk of $65 \mathrm{~mm}$ diameter was used as the bottom test piece which was rotated by a motor. The ball was made of JIS SUJ2 hardened steel (equivalent to AISI 52100 steel) with a Vickers hardness of $780 \mathrm{HV}$. The disk was made of 
S45C steel (AISI 1045 steel) with a Vickers hardness of $192 \mathrm{HV}$. Both test pieces had a surface roughness of 9 $\mathrm{nm} R a$.

Before starting the load-increasing test, the grease was applied to the disk surface such that the grease layer had uniform thickness was approximately $0.2 \mathrm{~mm}$. The rotating speed of the disk was maintained at a constant speed of $1.2 \mathrm{~mm} / \mathrm{s}$. The load applied to the ball was increased stepwise from $4.9 \mathrm{~N}$ (Hertzian contact pressure $\left.P_{\max }=1.2 \mathrm{GPa}\right)$ to $49.0 \mathrm{~N}\left(P_{\max }=2.6 \mathrm{GPa}\right)$ at increments of $4.9 \mathrm{~N}$ every two minutes, which corresponded to one rotational cycle of the disk. The tests were conducted at $40 \pm 1{ }^{\circ} \mathrm{C}$, and no grease was supplied during the test. The $\Lambda$ value calculated from base oil viscosity was about 0.1 , which implied the lubrication solely by the base oil was in boundary lubrication regime.

The friction coefficient and the degree of separation during load-increasing tests were measured. Friction coefficient was determined from the force detected by a sensor attached to the arm that held the upper test piece. The degree of separation was defined as the measured voltage divided by the applied voltage of $40 \mathrm{mV}$ in the circuit shown in Fig. 3. This was measured to evaluate the time percentage of direct metal-to-metal contact. The friction coefficient and the degree of separation were averaged over two minutes for each load. Another series of tests were conducted in which the tests were stopped at each of the loads and the surface roughness was measured in order to see the progress of surface damages.

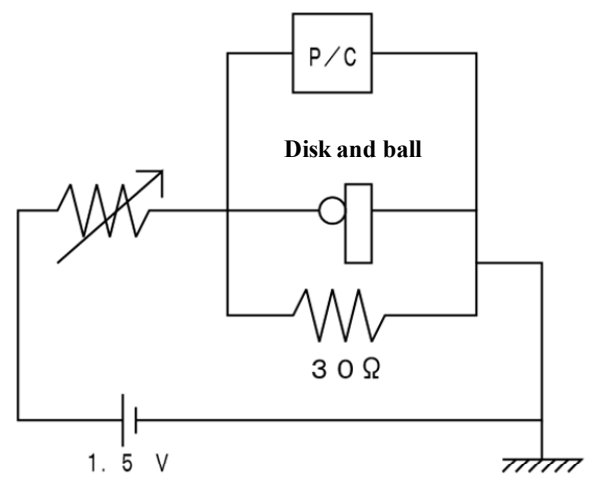

Fig. 3 Schematic of a circuit used to measure degree of separation

\section{Results and discussion}

\subsection{Friction and wear}

The results for the E03 oil-based grease are shown in Fig. 4. The common features found in the figures are gradual increase in the friction coefficient and gradual decrease in the degree of separation. Friction coefficient for the grease was lower than that for the E03 base oil, and the E03L grease with long fibers showed a lower friction coefficient than that for the E03S grease with short fibers.

The degree of separation with E03 was almost zero at $14.7 \mathrm{~N}$. It is likely that the oil film was broken down at the load when the degree of separation was zero. The loads at which the degree of separation became zero with the greases were higher than that with the base oil.

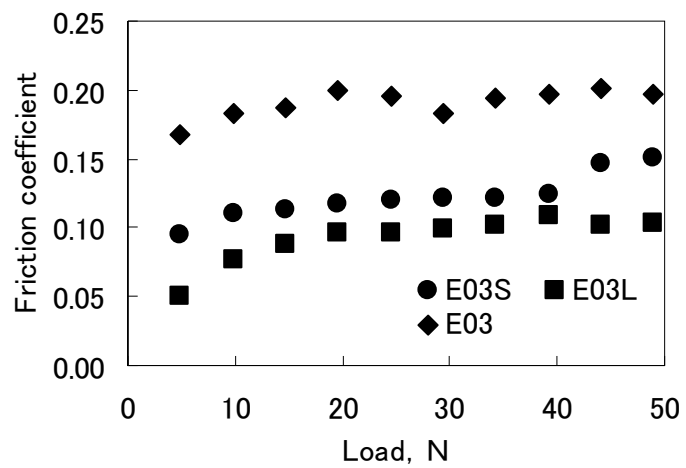

(a) Friction coefficient

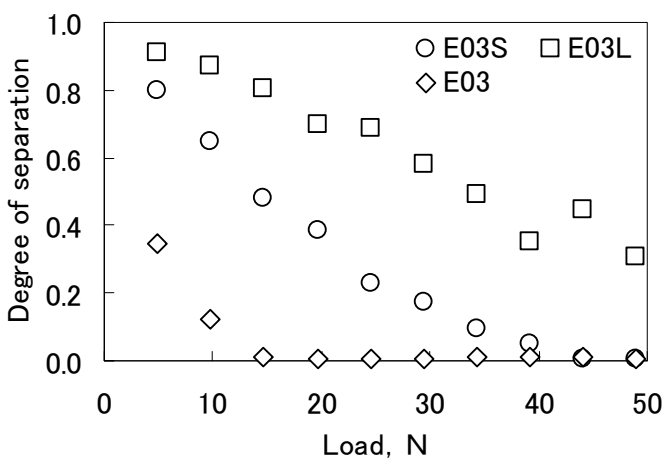

(b) Degree of separation

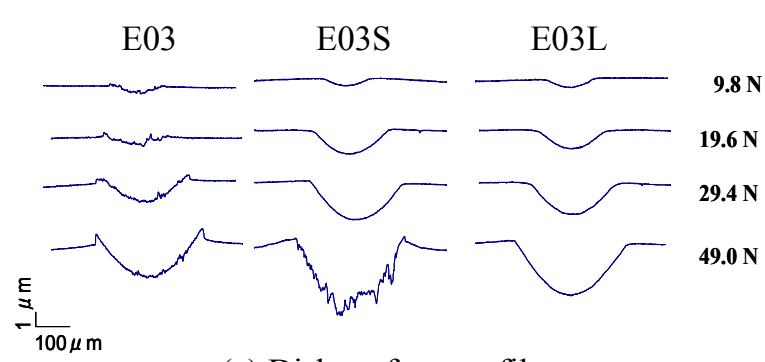

(c) Disk surface profiles

Fig. 4 Results of sliding tests

The degree of separation with E03L did not even reach zero at the end of the test. Disk surface profiles, Fig. 4(c), shows no surface damage was found on the disk surfaces in the tests with the greases E03S and E03L under non-zero degree of separation, although there was plastic deformation. However, the surface of $\mathrm{E} 03$ at $9.8 \mathrm{~N}$ under non-zero degree of separation showed slightly rough shape. This E03 profile suggested 
that partial break down of the oil film had occurred at the initial stage of the test. These suggest that the thickener deposited on the surfaces prevents metal-to-metal contact to afford lower friction under the conditions where breakdown of the base oil film occurs. This effect is more pronounced with the grease with long soap fibers.

The track on the disk surface after sliding under a load of $9.8 \mathrm{~N}$ with the E03S grease was observed with a laser-scanning microscope and a scanning electron microscope (SEM). The results are shown in Fig. 5.

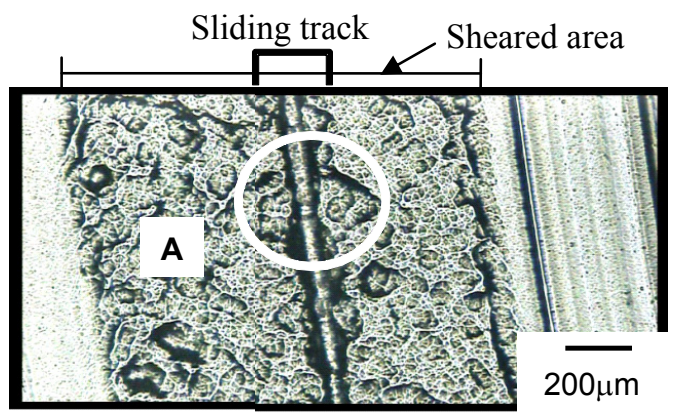

(a) Sheared grease around sliding track Granular-like grease

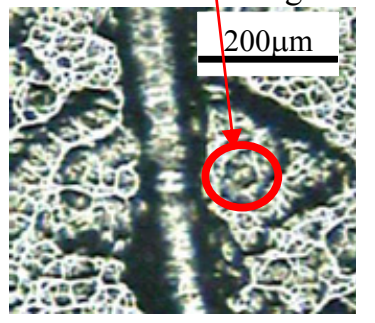

(b) Magnified view of $\mathrm{A}$ in (a)

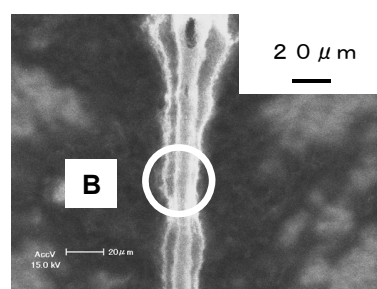

(d) SEM image of A in (a)

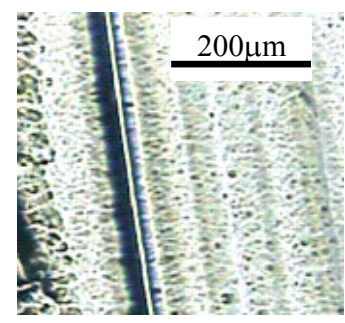

(c) Magnified view outside the sheared area

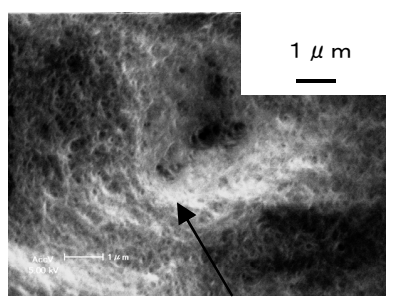

Thickener fiber

(e) Magnified view of B in (d)
Fig. 5 E03S grease on the disk surface after the test at $9.8 \mathrm{~N}$

The laser-scanning microscope image, Fig. 5(a), is taken at low magnification, while Figs. 5(b) and (c) are a magnified view of the sheared grease zone A indicated in Fig. 5(a), and that of the intact area outside the sheared zone. The images demonstrate that the grease, when subject to shear, adheres on the sliding track in a form of a line, while exhibits a granular-like appearance on both sides of the track. The SEM micrograph, Fig. 5(d), shows the same area as Fig. 5(b) after the area was rinsed with a solvent. Figure 5(e) is a magnified view of the area B in Fig. 5(d), which confirms the presence of thickener fibers. This strongly suggests that the grease soap fibers adhere on the contacting surfaces to form a protective film to provide better lubrication than the base oil.

Possible causes that make the grease with long soap fibers superior in lubrication capability to the grease with short soap fibers will be as follows. Firstly, the grease with longer soap fibers may have better lubricity; the film itself has lower frictional property, or the film is more capable of adhering and staying adhered on the sliding surface under shear. Secondly, the long soap fibers may be entrained more in quantity into the conjunction. They are investigated further in the following sections.

\subsection{Lubricity of soap fibers}

If the lubrication properties of the greases depend on those of the soap fibers, the frictional properties of the soap alone must depend on the length of the fibers. Sliding tests were conducted with soap fibers extracted from the two greases, E03S and E03L.

The procedure of the test is as follows. First, the grease is coated on the disk surface with thickness between $0.1 \mathrm{~mm}$ and $0.2 \mathrm{~mm}$. Then the disk was soaked in $n$-heptane for three minutes, taken out of $n$-heptane with its surface kept horizontal, and dried with a blower. Soaking and drying was repeated several times until a peak at $1740 \mathrm{~cm}^{-1}$ disappeared from the IR spectrum, as shown in Fig. 6, to ensure the removal of the base oil. The ball-on-disk tests were conducted with this disk for ten rotational cycles at a constant load of $19.6 \mathrm{~N}$. The friction coefficient for 10 cycles (20 minutes) was then determined. The rotating speed and the temperature were the same as those in the load-increasing tests.
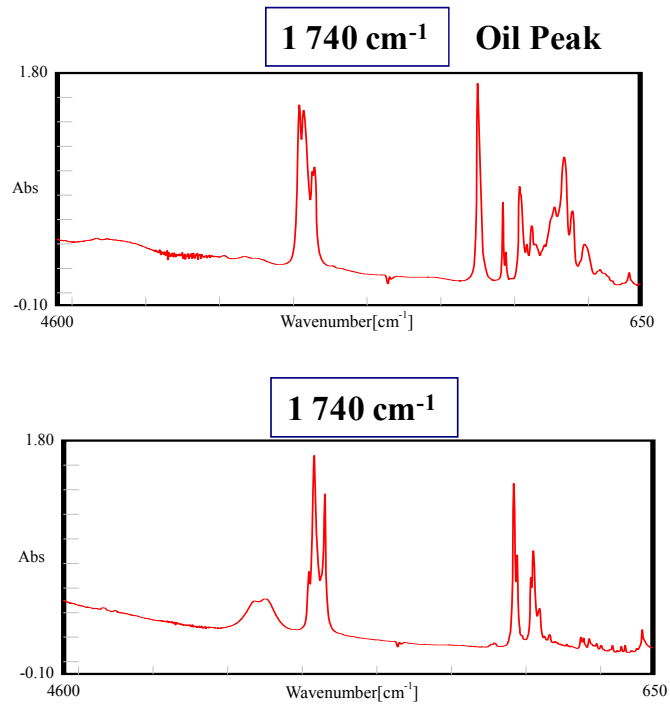

Fig. 6 IR spectrum of E03S grease (top) and soap extracted from the grease (bottom) 
The results are shown in Fig. 7. The friction coefficient with the soaps increases gradually with the number of cycles, and there is no substantial difference between the coefficient for the two fibers with different length. This suggests that the boundary films of the fibers of different lengths have similar lubricity; they provide the same friction coefficient and may similarly stay adhered on the track at least for the ten cycles of rotation.

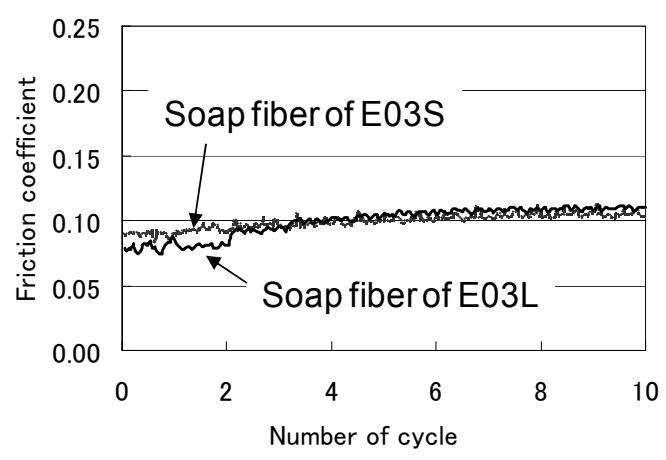

Fig. 7 Results of sliding test with soap fibers

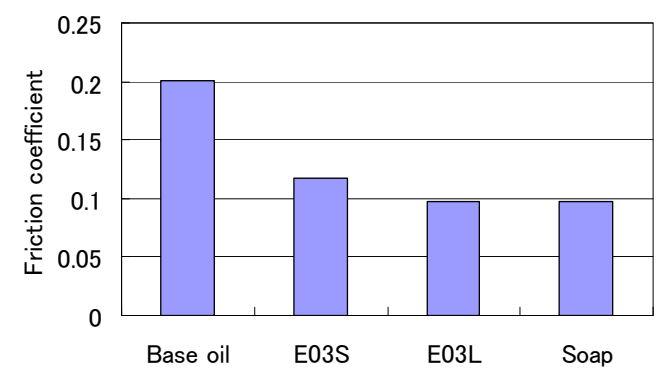

Fig. 8 Friction coefficient at $19.6 \mathrm{~N}$

Figure 8 compares the average friction coefficient with the soaps with those for base oil, E03S grease, and E03L grease at a load of $19.6 \mathrm{~N}$ shown in Fig. 4. The friction coefficient for the soaps is lowest, and those for the both greases are also much lower than that of the base oil, suggesting that the friction coefficient for the greases depend predominantly on the boundary film of the soaps. The difference in the friction coefficient for the two greases should now be ascribed to other factors than the lubricity or the adhesion of the fibers themselves.

\subsection{Entrainment of greases}

The grease coated on the disk surface initially works to lubricate the contact, but should gradually be removed from the track through repeated sliding. There may be two sources of further lubrication to maintain the low friction coefficient. One is the oil replenishment from the sides of the track, which however has little effect in the present tests as suggested in the preceding sections. Additional supply of the grease to the conjunction can then be only from the grease piled up at the inlet, where the moving surface acts to pull in the grease. Capability of the greases to be entrained into the conjunction between sliding surfaces are now examined in a couple of ways. One is to observe how the greases exist on the sliding track in the increasing-load tests. The other is what is called a partial coat test.

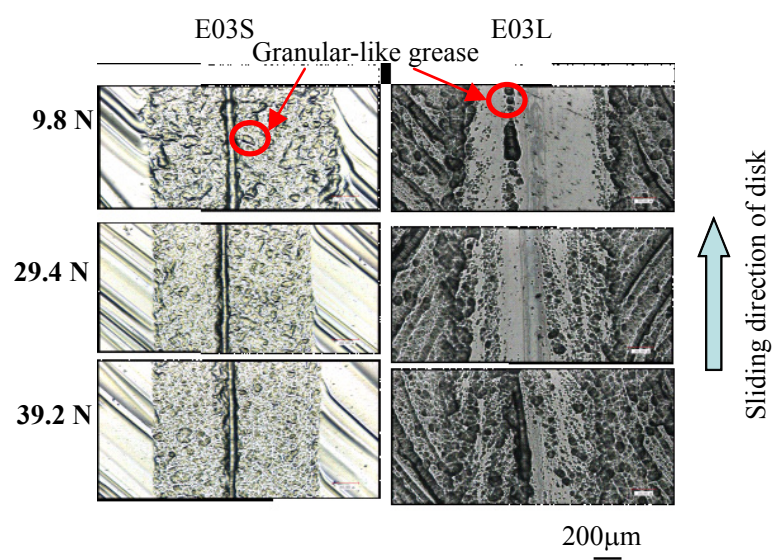

Fig. 9 Grease on the disk surface after the test at load indicated

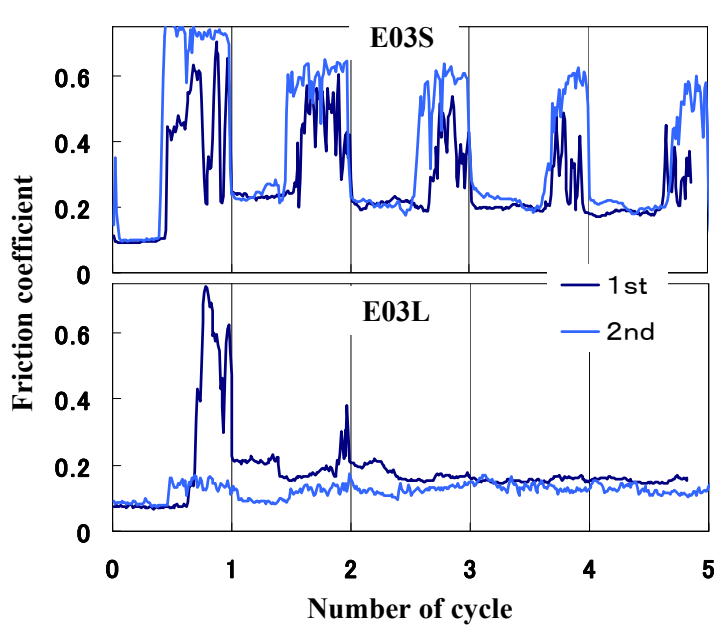

Fig. 10 Changes in friction coefficient with cycle in the partial coat tests

The disk surfaces were observed in the series of tests in which sliding was stopped at the end of each of the load steps. Figure 9 shows the greases on the disk surfaces after slid at the loads indicated. The photographs demonstrate that the size and volume of granular-like parts of E03S decreases at higher load, whereas this is not the case with E03L even at a load of $39.2 \mathrm{~N}$. Another series of tests, the partial coat grease tests, were to coat the greases only partly on the disk and to see how they spread by the traverse of the ball specimen. The greases were coated to $0.1 \mathrm{~mm}$ thick in fan shape on the disk surface to cover a quarter of the 
circumferential sliding track. The sliding tests were conducted at a sliding speed of $1.2 \mathrm{~mm} / \mathrm{s}$ under loads of $4.9 \mathrm{~N}$ or $9.8 \mathrm{~N}$ for 10 minutes, i.e. for five rotational cycles. The sliding was started such that the pin slid initially on the coated zone for a quarter of a cycle.

Figure 10 shows the changes in the friction coefficient with time in the tests at $9.8 \mathrm{~N}$. In each of the charts are plotted results of two tests conducted under the same test conditions. With the E03S grease, the friction coefficient clearly exhibits the low and high phases in each of the cycles. The low coefficient is caused by grease lubrication, while the high coefficient corresponds to unlubricated sliding. The low coefficient phase extends for more than a quarter of the cycle, which suggests that some amount of the grease has been supplied to the track during sliding. The duration of the low friction phase increases gradually with the cycle, though the phase of high and fluctuating coefficient is still seen in the fifth cycle. In contrast, the high coefficient phase is seen only in the first cycle with the E03L grease; the friction coefficient almost settles down at a low level after the third cycle.

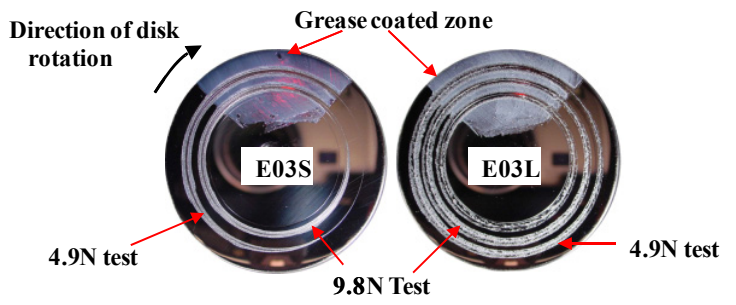

Fig. 11 Disk specimens after the partial coat grease tests

Figure 11 shows the tracks on the disk specimens after the tests. The photographs demonstrate that both greases have spread into the no grease coated zone along the track on the disks. The greases piling up at the inlet have been entrained by the motion of the disk, and left behind the conjunction. The traces of the E03S grease extend beyond three quarters of the track, while those of the E03L grease cover the entire track. This agrees with the changes in the friction coefficient in the fifth cycle shown in Fig. 10, and indicates the difference in the capability of the two greases to be entrained at the inlet. The difference in how well the greases are entrained, and consequently the difference in the behaviors of the friction coefficient, are more pronounced in the tests conducted under a load of $4.9 \mathrm{~N}$.

Figure 12 shows the steel balls observed after the partial coat tests. The photographs show that the greases adhere on the steel balls on the two sides of the surfaces that have been the inlet and the outlet of the contact. It was observed in the partial coat tests that the grease adhered and accumulated on the front side of the ball as it traveled through the greased zone. As the ball passed through the non-greased area, a part of the grease that had accumulated in front of the ball was drawn in the sliding direction in and around the conjunction, and left behind the ball and on the disk track. This worked as a lubricant to lower the friction coefficient. It was also observed, with the E03L grease, some of the grease left on the disk track was entrained again in the subsequent cycles. The amounts of the E03L grease accumulated on the front and the back are clearly greater than those of E03S. The E03L grease with longer soap fibers thus has more capability to be entrained between the sliding surfaces and to exist on the sliding track to provide better lubrication than the E03S grease.
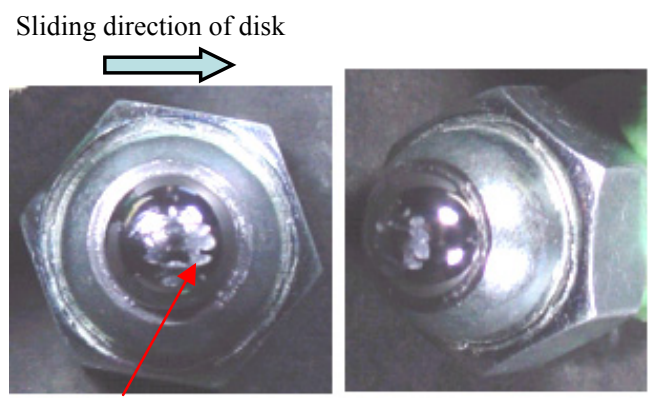

grease

(a) E03S
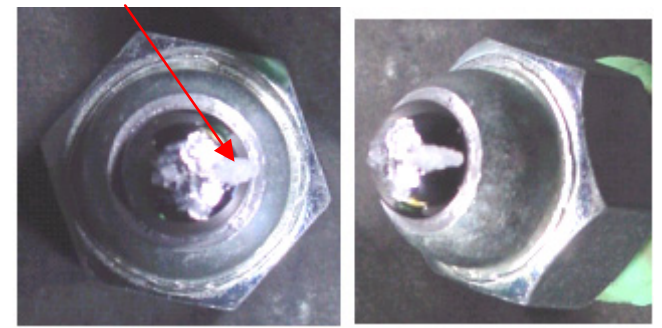

(b) E03L

Fig. 12 Grease adhered on the balls

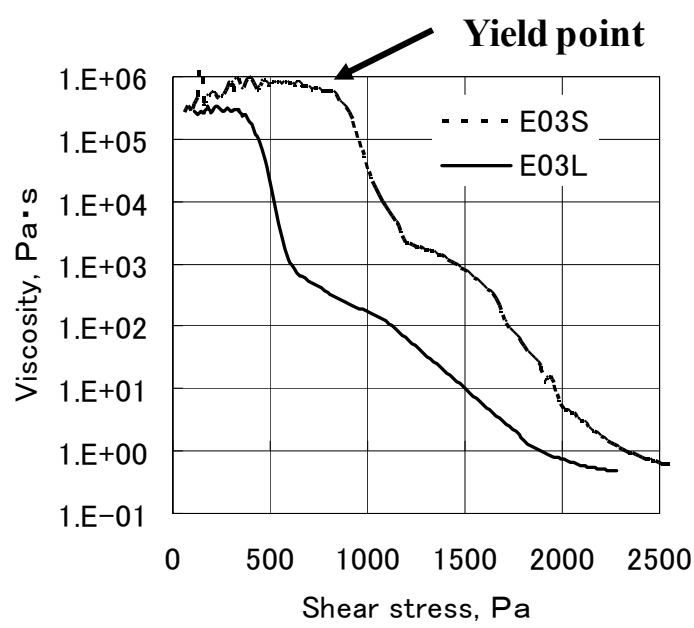

Fig. 13 Rheometer test results

\subsection{Rheology of grease}

In order to study relationships between the capability of the greases to be entrained on the sliding track and their rheological properties, changes in the viscosity of the greases with shear stress were determined with a 
rheometer. The results are shown in Fig. 13. The E03L grease exhibits lower viscosity and yields at lower shear stress than the E03S grease, implying that the former may deform and flow more easily when subject to shear between solid surfaces. It is likely that this has resulted in the better entrainment capability of the E03L grease. This is similar to the dependence of yield stress reported by the Hurley and Cann ${ }^{11)}$.

Williamson reported that when grease was introduced to a rolling contact surfaces, the soap fibers were broken down and dispersed in particulate form in the base oil ${ }^{16)}$. It is possible that the longer soap fiber structure of the E03L grease is more resistant to damage than the E03S grease, the E03L grease soap fibers are less likely to be broken into smaller pieces, and provides the capability to be entrained on the sliding surface continuously.

\section{Conclusions}

The effects of soap fiber lengths in boundary lubrication of greases were studied using a ball-on-disk test rig. The results are summarized as follows.

(1)The greases tested showed a lower friction coefficient than that with the base oil alone. Metal-to-metal contact as detected by the electrical contact resistance measurement occurred at higher load with the greases than with the base oil alone.

(2)The grease with longer soap fibers had a lower friction coefficient than the grease with shorter soap fibers.

(3)The soap fiber itself provided good boundary film, which resulted in the low coefficient of friction with the greases. It was also shown that the fiber length did not substantially affect the lubricity of the soap fibers.

(4)The partial coat tests revealed that the cause of the better boundary lubrication of the grease with longer soap fibers was its higher capability to be entrained into the conjunction than the grease with shorter soap fibers.

(5)It was suggested that the better entrainment capability of the grease with longer soap fibers was caused by its lower viscosity and lower yield stress.

\section{References}

[1] Boner, C. J., "Manufacture and Application of Lubricating Grease," Reinhold Publishing Corporation, New York, 1954, 904-913.

[2] Neale, M. J., eds., "The Tribology Handbook, Second Edition," Butterworth-Heinemann, Oxford, 1995, C4.1-C4.4.

[3] Iso, K., Yokouchi, A. and Takemura, H., "Research Work for Clarifying the Mechanism of White
Structure Flaking and Extending the Life of Bearings," SAE Technical Paper, 2005-01-1868, 2005.

[4] Ward, W. C., Denis, R. A., Najman, M. and Groote C. L., "EP Additive Response and Tribochemical Film Formation in Lithium and Lithium Complex Grease," NLGI Spokesman, 71, 7, 2007, 14-21.

[5] Kita, T. and Yamamoto, Y., "Structure Changes in Manufacturing Process of Lithium 12-Hydroxystearate Grease," J. Japan Soc. Tribologists, 38, 1, 1993, 69-76. (in Japanese)

[6] Kita, T. and Yamamoto, Y., "The Relations between Fibrous Structures and Manufacturing Conditions at Lithium 12-Hydroxystearate Lubricating Grease," J. Japan Soc. Tribologists, 40, 2, 1995, 161-168. (in Japanese)

[7] Yamamoto, Y., Gondo, S. and Kita, T., "Effect of Soap Fiber Structure of Lithium 12-Hyudroxystearate Grease on Frictional Characteristics under Boundary Lubricating Condition," J. Japan Soc. Tribologists, 42, 6, 1997, 462-469. (in Japanese)

[8] Kimura, H., Imai, Y. and Yamamoto, Y., "Study on Fiber Length Control for Ester-Based Lithium Soap Grease," Trib. Trans., 44, 3, 2001, 405-410.

[9] Cann, P. M., "Grease Lubricant Film Distribution in Rolling Contacts," NLGI Spokesman, 61, 2, 1997, 22-29.

[10] Cann, P. M. and Lubrecht, T., "Mechanisms of Grease Lubrication in Rolling Element Bearings," COST 516 Tribology Symp., 1998, 61-75.

[11] Hurley, S. and Cann, P. M., "Starved Lubrication of EHL Contacts - Relationship to Bulk Grease Properties," NLGI Spokesman, 64, 2, 2000, 15-23.

[12] Hurley, S. and Cann, P. M., "Infrared Spectroscopic Characterization of Grease Lubricant Films on Metal Surfaces," NLGI Spokesman, 64, 7, 2000, 13-21.

[13] Eriksson, E., Wikström, V. and Larsson, R., "Grease Soap Particles Passing through an Elastohydrodynamic Contact under Side Slip Conditions," Proc. Instn. Mech. Engrs., Part J, 214, 2000, 317-325.

[14] Cann, P. M. and Hurley, S., "Friction Properties of Grease in Elastohydrodynamic Lubrication," NLGI, 66, 1, 2002, 6-15.

[15] Cann, P. M., "Grease Lubrication of Rolling Element Bearings - Role of the Grease Thickener," Lubrication Science, 19, 2007, 183-196.

[16] Williamson, B. P., "An Optical Study of Grease Rheology in an Elastohydrodynamic Point Contact under Fully Flooded and Starvation Conditions," Proc. Instn. Mech. Engrs., 209, 1994, 63-74. 